ISSN: 0514-7336

DOI: http://dx.doi.org/10.14201/zephyrus201576121139

\title{
LA CIUDAD DE DERTOSA DURANTE EL ALTO IMPERIO. LA OCUPACIÓN DEL ÁREA SUBURBIAL DEL BARRANCO DEL RASTRE
}

\section{The city of Dertosa in the Early Roman Empire. The occupation of the suburban area of the Rastre ravine}

\author{
Jordi Diloli Fons*, Ramón Ferré Anguix*, Ramón Járrega Domínguez** y Jordi Vilà Llorach* \\ * Grup de Recerca Seminari de Protohistòria i Arqueologia (GRESEPIA)-URV. Avda. Catalunya, 35. 43002 Tarrago- \\ na.Correo-e: jordi.diloli@urv.cat; r.ferre@hotmail.es; jordivilallorach@gmail.com \\ ** Institut Català d'Arqueologia Clàssica (ICAC). Plaça Rovellat, s/n. 43003 Tarragona. Correo-e: rjarrega@icac.cat
}

Recepción: 7/05/2015; Revisión: 6/07/2015; Aceptación: 8/09/2015

BIBLID [0514-7336 (2015) LXXVI, julio-diciembre; 121-139]

\begin{abstract}
Resumen: El estudio de la evolución del urbanismo antiguo de la ciudad de Tortosa es uno de los principales proyectos del Grup de Recerca Seminari de Protohistoria i Arqueologia de la Universitat Rovira i Virgili, siendo la reconstrucción urbana de la ciudad ibérica y romana el más destacado objetivo del proyecto. A partir de la interpretación de los trabajos arqueológicos llevados a cabo en el municipio, sobre todo de las intervenciones efectuadas por nuestro equipo en el casco urbano de Tortosa durante los últimos diez años, presentamos un primer acercamiento a la realidad de la ocupación romana de la antigua Dertosa, concretamente una propuesta de reconstrucción urbanística de un sector de la ciudad centrado en el barranco del Rastre, una zona extramuros que formaba parte de un suburbio meridional de la ciudad, probablemente ligado al funcionamiento del puerto fluvial. Con estas intervenciones hemos podido comprobar como los espacios edificados se adaptan al terreno mediante la construcción de plataformas escalonadas, salvando así las dificultades morfológicas impuestas por una orografía compleja.

Palabras clave: Urbanismo; topografía; terrazas; puerto fluvial; río Ebro; época romana.
\end{abstract}

AвSTRACT: The study of the evolution of urban planning of the ancient city of Tortosa is one of the main projects of the Grup de Recerca Seminari de Protohistoria i Arqueologia of the Rovira i Virgili University. The reconstruction of the urban topography of the Iberian and Roman city is the foremost goal of the project. Starting from the interpretation of the archaeological work carried out in the city, especially the interventions led by our team in Tortosa during the last ten years, we offer a first approach to the reality of the Roman occupation of ancient Dertosa. It is a proposal of urban reconstruction of a section of the city focused on the Rastre ravine, an extramural area that was part of a southern suburb of the city, probably linked to the operations that took place at the river port. We have seen as the built spaces were adapted to the ground by building staggered platforms, and thus overcoming the morphological constraints imposed by a complex topography.

Key words: Urbanism; topography; terraces; fluvial port; river Ebro; Roman time.

(c) Universidad de Salamanca

Zephyrus, LXXVI, julio-diciembre 2015, 121-139 


\section{Introducción ${ }^{1}$}

El barranco del Rastre ha sido a lo largo de los siglos uno de los condicionantes naturales del urbanismo de la ciudad de Tortosa; su situación y características lo convierten en uno de los límites naturales del área habitada, a la vez que vía de acceso a la ciudad, zona cementerial o incluso, según se podría extraer de los últimos descubrimientos arqueológicos, área portuaria. Las dificultades para asimilar el barranco a nivel urbanístico quedan plasmadas en su difícil integración en la ordenación del crecimiento de la ciudad, siendo su carácter irregular y peligroso al recoger y transportar el agua de los cerros que rodean la ciudad por su lado norte. Este hecho, así como su tardía solución, pues su cauce no fue completamente urbanizado hasta muy entrado el s. XIX, provocó que las violentas avenidas que siguieron recorriéndolo de vez en cuando causaran diversos accidentes mortales hasta bien entrado el s. xx (Abril, 1931; Bayerri, 1935, 1960).

Situado entre los cerros del Sitjar al E y de la Zuda -donde se ubicaría un importante asentamiento ibérico- en el o, el barranco desemboca en el margen izquierdo del río Ebro en sentido oblicuo. A pesar de este carácter periférico respecto al corazón de la ciudad antigua, tanto ibérica como romana, y en cierto modo también de la medieval, el área del Rastre es un sector particularmente rico en hallazgos y noticias arqueológicas a lo largo de los ss. XviII, xIx y xx. En el momento en que se emprenden los primeros trabajos arqueológicos con metodología científica - para lo que debemos esperar hasta los años ochenta del s. $\mathrm{xx}$, con las intervenciones en la plaza de l'Olivera y, sobre todo, en la plaza Alfonso XII, cerca de la desembocadura del barranco-, ya era conocido el uso de esta zona como espacio de necrópolis de época romana, habiéndose producido frecuentes descubrimientos de restos humanos, a menudo cubiertos por fragmentos de ánfora, así como puntuales ejemplos de sepulcros con un cariz más monumental, como la cupa descubierta durante unas obras en la c/ Mercaders en 1973 (Miravall, 1984).

Durante los primeros años del s. Xxi la actividad constructiva y el interés científico motivaron el

1 Este trabajo se enmarca en el proyecto Adaptación al medio y evolución sociopolítica de las comunidades asentadas en el valle del Ebro desde el Bronce final hasta época romana (HAR2012-33395), subvencionado por el MINECO y desarrollado bajo la dirección de J. Diloli Fons. aumento de las intervenciones arqueológicas en este espacio, hasta el punto de que actualmente se trata de la zona mejor conocida arqueológicamente de la ciudad. Buena parte de este avance se debe a los trabajos del Grup de Recerca Seminari de Protohistòria i Arqueologia (GRESEPIA) de la Universitat Rovira i Virgili, que ha centrado una de sus líneas de investigación en el estudio del desarrollo urbano de Tortosa desde sus orígenes hasta la Edad Media. En este estudio se presenta una visión actualizada de estos trabajos, poniendo de manifiesto el carácter urbano o periurbano del sector del Rastre ya durante el alto imperio.

\section{Presencia de restos arqueológicos de época romana en el Barranco del Rastre}

La investigación efectuada en este lugar en época moderna, dejando de lado los hallazgos relacionados con el mundo funerario (Navarro, 2008), se inicia con el descubrimiento de estructuras murales romanas en la plaza de l'Olivera entre 1982 y 1984 (Curto et al., 1986), aunque la documentación generada por esta intervención es escasa. A pesar de la frecuente mención de esta intervención en la literatura especializada, para época altoimperial sólo se puede asegurar la exhumación de un muro de encofrado situado a unos $6 \mathrm{~m}$ sobre el nivel del mar. Este muro tiene una anchura de unos $50 \mathrm{~cm}$ y sigue un trazado E-O, aproximadamente el mismo que el cauce del barranco, apoyándosele varias estructuras tardías de factura más grosera. El carácter parcial de los hallazgos -el muro de encofrado se conoce en una longitud de apenas $1,5 \mathrm{~m}-$, no ha impedido que se haya interpretado como un dique relacionado con el área portuaria de la ciudad. Esta identificación proviene de los estratos arcillosos que se le apoyan -posibles indicios de avenidas-, así como de la abundancia de material anfórico recogido en sus alrededores. De hecho, se trata de una interpretación que sigue los parámetros planteados por el historiador R. Miravall, que ya sugería una hipotética situación del puerto romano en el mismo barranco del Rastre (Miravall, 1988). En cuanto a la cronología de la estructura, sus excavadores databan el muro entre los ss. II y vi d. C. (Curto et al., 1986), de modo que si tomamos como referencia una cronología inicial del siglo II, podríamos relacionarlo con 

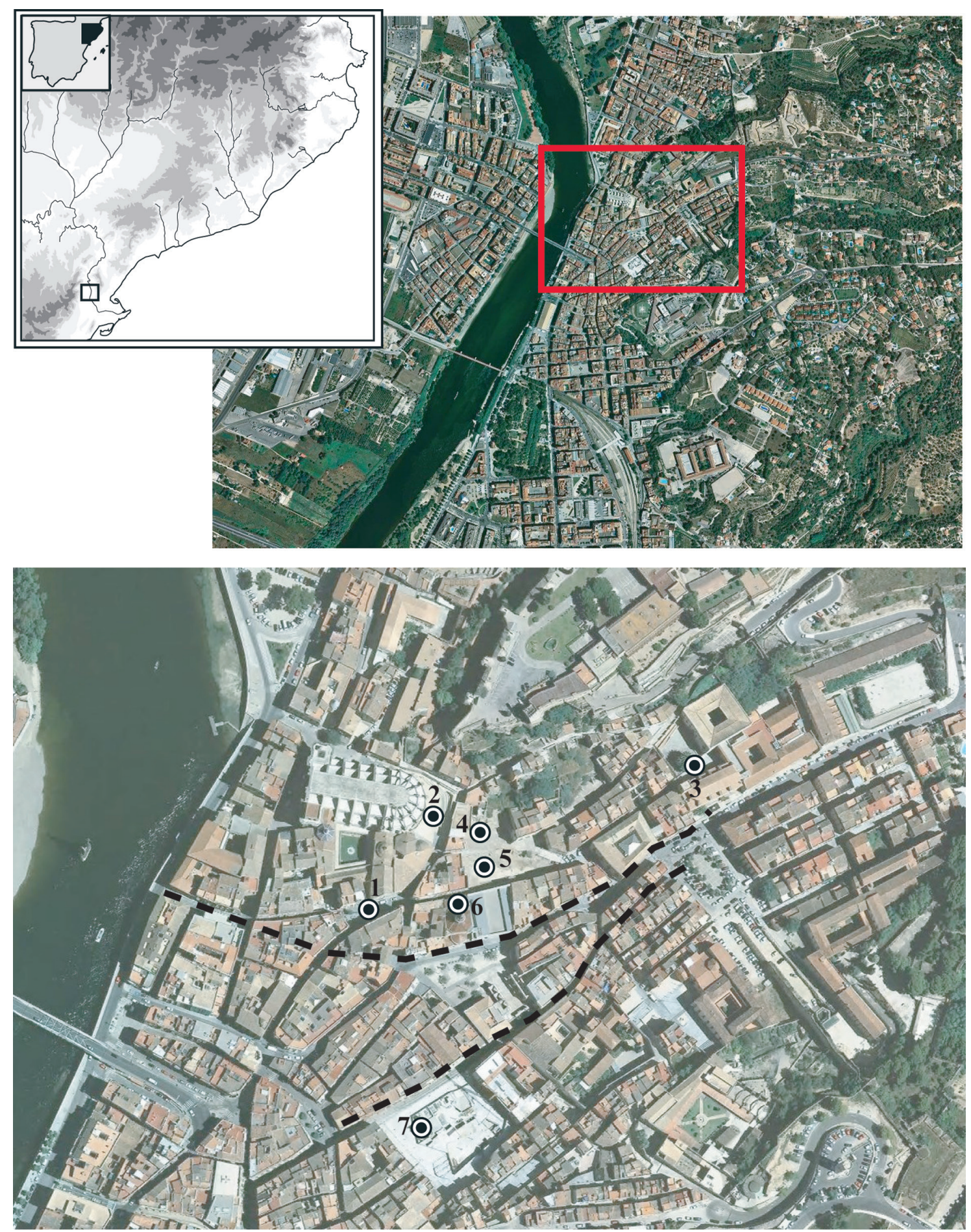

Fig. 1. Tortosa. Localización de las principales intervenciones arqueológicas citadas en el texto: 1) plaza de l'Olivera; 2) plaza del ábside; 3) c/ Sant Domènech; 4) cl Sant Felip Neri; 5) cl de la Mercè; 6) Cripta de la Reparación; 7) cl Montcada; punteado el posible cauce del barranco del Rastre en época romana. 


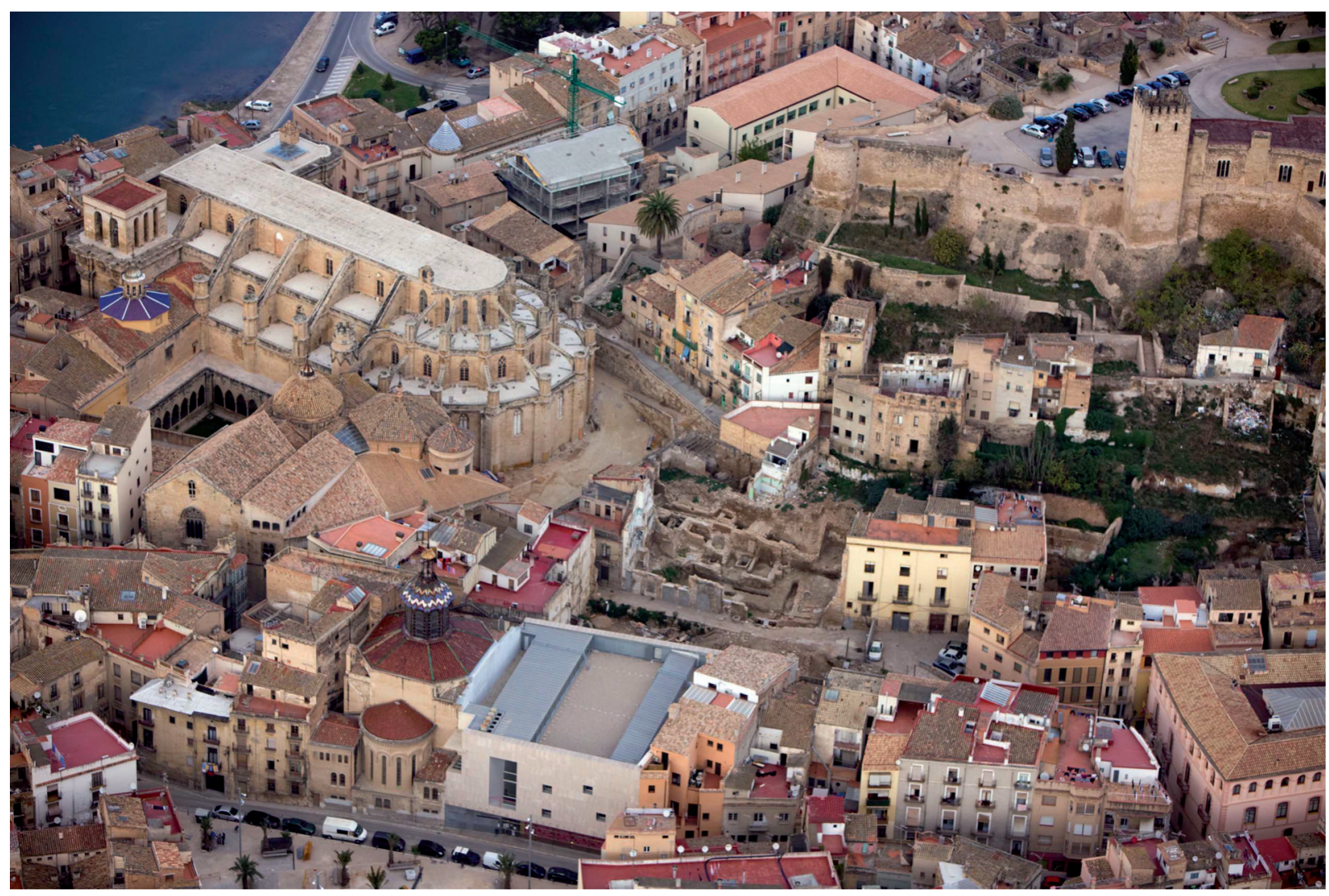

Fig. 2. Vista aérea del sector del margen derecho del barranco del Rastre; puede observarse la zona del ábside de la Catedral, el espacio de Sant Felip Neri-cl de la Mercè y en primer término la iglesia donde se ubica la Cripta de la Reparación.

la segunda fase del conjunto estructural exhumado en la c/ Montcada, como veremos más adelante. Vale la pena destacar la ausencia de tumbas bajoimperiales y tardoantiguas en la excavación de la plaza de l'Olivera, sobre todo considerando que éstas están presentes en casi todas las excavaciones con estratigrafía romana que se han llevado a cabo en las zonas cercanas al barranco.

Otra intervención que ha aportado datos supuestamente relacionados con este complejo portuario fue la dirigida por E. Barrasetas en la plaza de Alfonso XII, en la que se documentó un pavimento de guijarros y mortero de cal que fue datado a mediados del s. II d. C. (Barrassetas, 1988).

Los resultados de las excavaciones de las plazas de l'Olivera y Alfonso XII, junto con la documentación de otros restos arqueológicos de poca entidad, aparecidos generalmente fuera de contexto, así como la geomorfología del terreno, fueron claves para que J. M. V. Arbeloa $(2000,2008)$ concibiera muy acertadamente la existencia de un suburbium meridional de la ciudad de Dertosa, situado fuera de la muralla, coincidente en buena medida con los restos que presentamos en este estudio. En realidad todavía se conoce muy poco del trazado de la muralla romana de Dertosa, si bien al tratarse de una zona con abundantes hallazgos funerarios, la opinión más generalizada ha sido considerar el Rastre como un espacio externo al pomerium.

\subsection{Intervenciones en la c/ Sant Domènech}

A principios del año 2000, el GREsEria efectuó diversas intervenciones arqueológicas en las calles Sant Domènech y Sant Felip Neri que, entre otros datos 
de épocas más recientes, aportaron también evidencias de una ocupación protohistórica del cerro de la Zuda, una colina que enmarca el margen derecho del barranco del Rastre cerca de su desembocadura. Entre los materiales recuperados en las excavaciones se encontraron cerámicas modeladas a mano y fragmentos de ánfora fenicia procedente del s de la Península. Este hecho, a pesar de que los materiales se hallaron en posición secundaria, pues seguramente habían rodado desde su posición original en la cima del cerro hasta la parte más baja del mismo, confirmaba la exis-

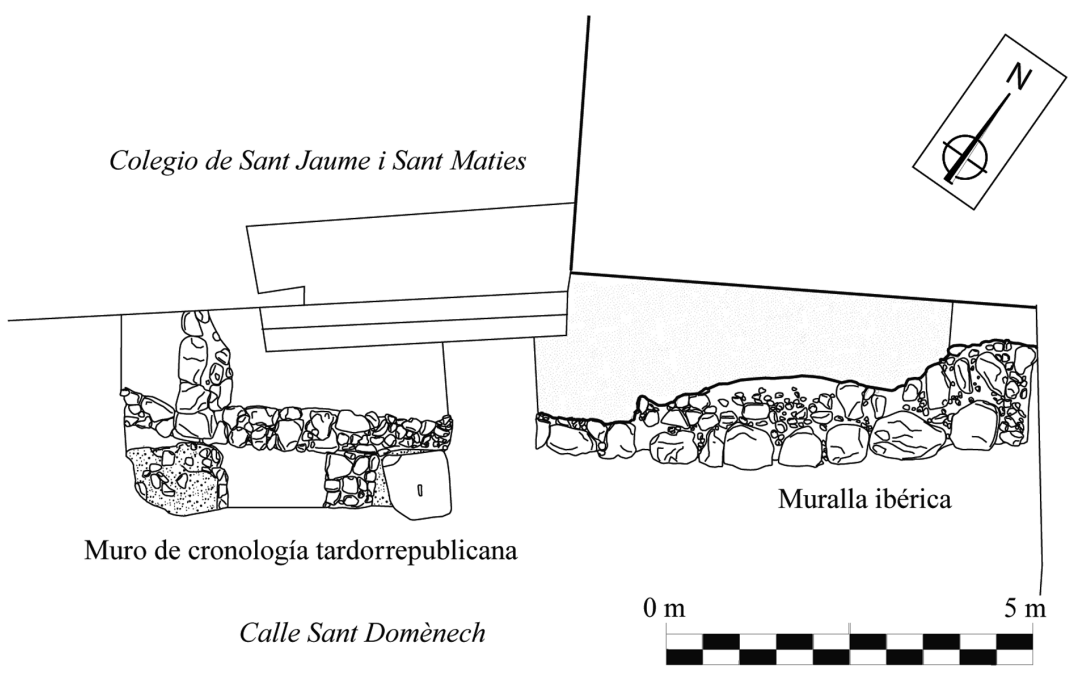

Fig. 3. Planta de las estructuras ibéricas y romanas localizadas en la c/ Sant Domènech. tencia de un asentamiento de la Primera Edad del Hierro en este lugar, con una continuidad en época ibérica (Diloli y Ferré, 2008; Diloli et al., 2012, 2013). Los trabajos en este espacio permitieron localizar diversas estructuras, de las cuales las más antiguas correspondían a un potente muro de 1,5 m de anchura, localizado en la c/ Sant Domènech, con una longitud conservada de 5,40 m, continuando uno de sus extremos por debajo del convento de Sant Jaume i Sant Maties. Se trata de una estructura definida en su cara externa por dos hiladas de bloques de piedra no escuadrada, en cuya parte posterior se acumula una gran cantidad de piedra pequeña y mediana, a modo de relleno, sin cara interna, apoyado en el terreno arcilloso de la ladera de la montaña. Es pues de un muro de aterrazamiento que salva un importante desnivel, revistiéndolo con piedra, presumiblemente asociado a una obra defensiva. Teniendo en cuenta que sólo conocemos su base, el alzado original podría superar con facilidad los 3 $\mathrm{m}$ de altura, por aventurar una cifra que podría ser bastante mayor. Los estratos de abandono que se le apoyan, con presencia de fragmentos de campaniense A, indican que ya en el s. II a. C. su base empezaba a cubrirse de sedimento, por lo que es posible que su erección se pueda situar en un momento no muy anterior, tal vez a partir de mediados o finales del s. III a. C. Está claro que se trata de una construcción ibérica y por sus características de anchura, técnica constructiva y situación topográfica, no cabe interpretarse

sino como hemos indicado, como una fortificación avanzada diseñada para proteger el núcleo ubicado en la Zuda, hasta hace poco tiempo conocido sólo por datos historiográficos y por restos de cerámica fuera de contexto recuperada de los alrededores del cerro. Esta estructura, que ya había sido amortizada en la primera mitad del s. I d. C., constituye por sí sola la primera evidencia de transformación antrópica radical de la geomorfología del Rastre, antes de la dominación romana, con la constitución de al menos una plataforma defensiva en la parte media de la ladera, aprovechando el cauce del barranco como foso natural (Diloli y Ferré, 2008; Diloli et al., 2011, 2013).

\subsection{Intervenciones en la c/ Sant Felip Neri}

En la mayoría de las excavaciones llevadas a cabo por nuestro equipo en la ladera meridional de la Zuda durante los últimos años, se ha logrado alcanzar niveles de ocupación de cronología julioclaudia, hasta el punto de que se puede hablar de una urbanización sistemática de este sector entre la parte superior del cerro y un límite hipotético que, de momento, podemos ubicar entre las calles de la Mercè y Nou del Vall. Una de las intervenciones más desveladoras fue la efectuada en la c/ Sant Felip Neri (Járrega et al., 


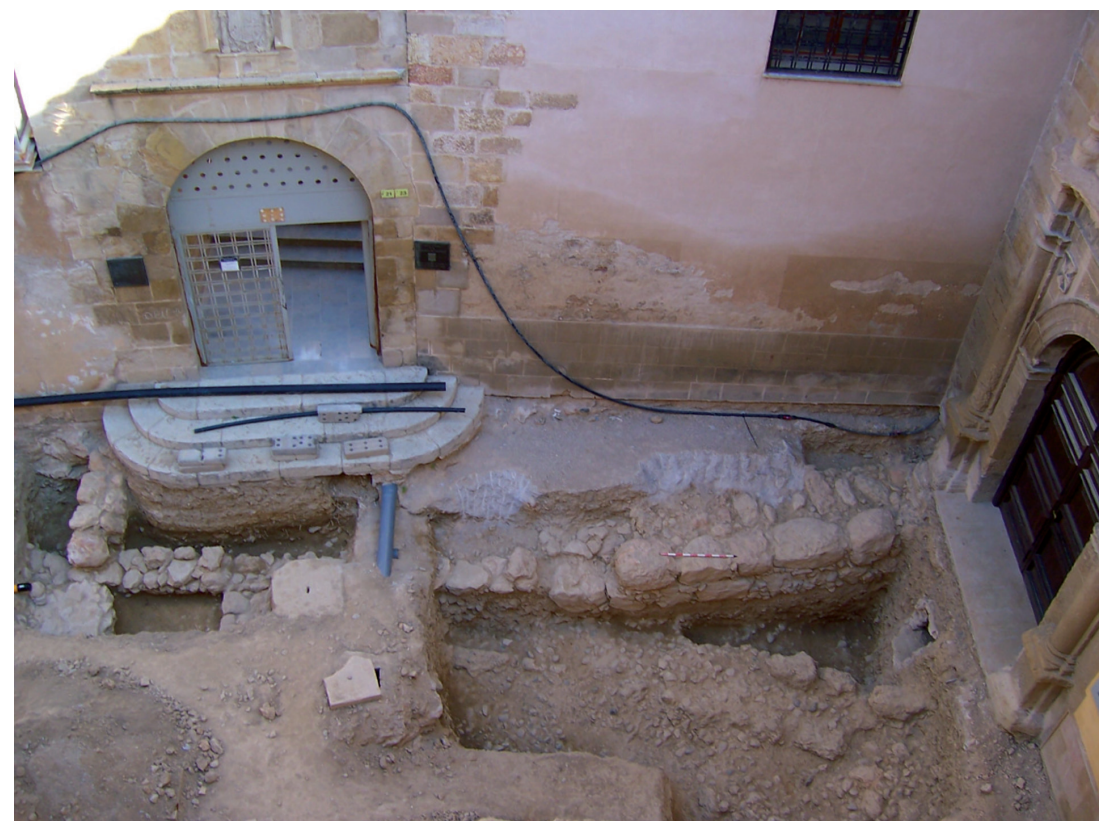

FIG. 4. Vista general de la excavación de la c/ Sant Domènech; se observan el paramento ibérico y las estructuras romanas.

2014) ${ }^{2}$, localizándose los restos de cronología romana en el extremo de una terraza constructiva, donde se han descubierto los restos de un edificio en el que se observan dos fases de ocupación bien diferenciadas. Se conoce una primera fase con una datación un tanto imprecisa debido a las limitaciones materiales de la intervención, pero que podría situarse en un contexto augústeo, en un momento anterior al cambio de era, en la que destaca la presencia de un largo muro de aterrazamiento [A] en paramento de sillarejo, de 12,5 m de longitud visible, si bien su extremo este se pierde por debajo del corte del límite de la excavación, y, a pesar de que se interrumpe, es muy posible que también se extendiera más allá por su extremo oeste. Su anchura se sitúa en el entorno de los $50 \mathrm{~cm}$ y tiene una altura conservada de unos $3 \mathrm{~m}$. Apoyados a este muro aparecen dos tabiques paralelos $[\mathrm{B}]$ y $[\mathrm{C}]$ con características similares, de poco más de 1,5 m, que desaparecen como consecuencia de un brusco recorte producido en un momento

2 También Diloli, J.; Ferré, R.; Járrega, R. y Vilà, J.: "Nuevas aportaciones para el conocimiento de la antigua Dertosa. La excavación de la calle Sant Felip Neri”. En Actas XVIII Congreso Internacional de Arqueología Clásica (Mérida, 2013), en prensa muy posterior que se extiende en sentido longitudinal. Estos muros dan lugar a tres espacios, HI, H2, у H3; los dos primeros, н1 у н2, seguramente contarían con un sencillo pavimento de tierra, mientras que $\mathrm{H} 3$ tenía un pavimento de guijarros $y$ cal, formando un conjunto al que se le añaden varios muros situados al noreste, colocados en paralelo o en perpendicular respecto al muro de aterrazamiento principal $[\mathrm{A}]$. Se trata de los únicos restos conservados de un mismo complejo del que posiblemente habría formado parte el edificio descrito, pero en una cota superior, y por lo tanto más expuesto a los recortes ocasionados por la actividad constructiva de épocas posteriores, siendo así que la parte s-SE del edificio está perdida.

La segunda fase está mejor datada gracias al material contenido en el relleno del aumento de cota de los niveles de circulación del edificio, destacando la presencia de terra sigillata itálica, con varios ejemplares de Conspectus 4.1, 4.4, 6.2, 14.1, 22.1, 33, etc., así como también de fragmentos de cerámica de paredes finas de la forma Mayet 1 o 2, hecho que nos sitúa la reforma de este espacio en algún momento del primer cuarto del s. I d. C., eliminándose la pequeña habitación intermedia, quedando únicamente dos salas. En los primeros momentos posteriores a la reforma, el suelo de $\mathrm{H} 1$ contó con un modesto pavimento de cal, que seguramente se desgastó rápidamente por el uso. Las pequeñas reformas que se documentan más adelante no afectaron la estructura espacial, aunque demuestran que existió un cierto mantenimiento de los espacios. Este hecho es visible en el estucado del muro [c], en el que se observan varias capas de pintura. También se da la formación en $\mathrm{H} 1$ de un nuevo nivel de uso por encima del anterior pavimento de cal, en este caso una mera capa de tierra fina que constituye la última fase de ocupación del espacio antes de su abandono.

Con el abandono del edificio, las habitaciones $\mathrm{H} 1$ y $\mathrm{H} 2$ se convirtieron en un vertedero de escombros. Es posible que el intervalo entre su abandono y el 
relleno de materiales constructivos no fuera muy dilatado, dado que se han recuperado varios elementos cerámicos in situ en un excelente estado de conservación, lo que sugiere que no hubo una frecuentación de los espacios antes de los vertidos. Entre éstos destacan un par de fragmentos de la forma Ritt. 8 en terra sigillata hispánica y un vaso de cerámica africana de cocina Hayes 200, además de una serie de jarras comunes, una de las cuales es de probable procedencia africana. El material anfórico está representado por dos ejemplares enteros de Beltrán IIB, una Dressel 20, una anforita que imita en miniatura la misma forma Dressel 20 y una segunda anforita de proce-

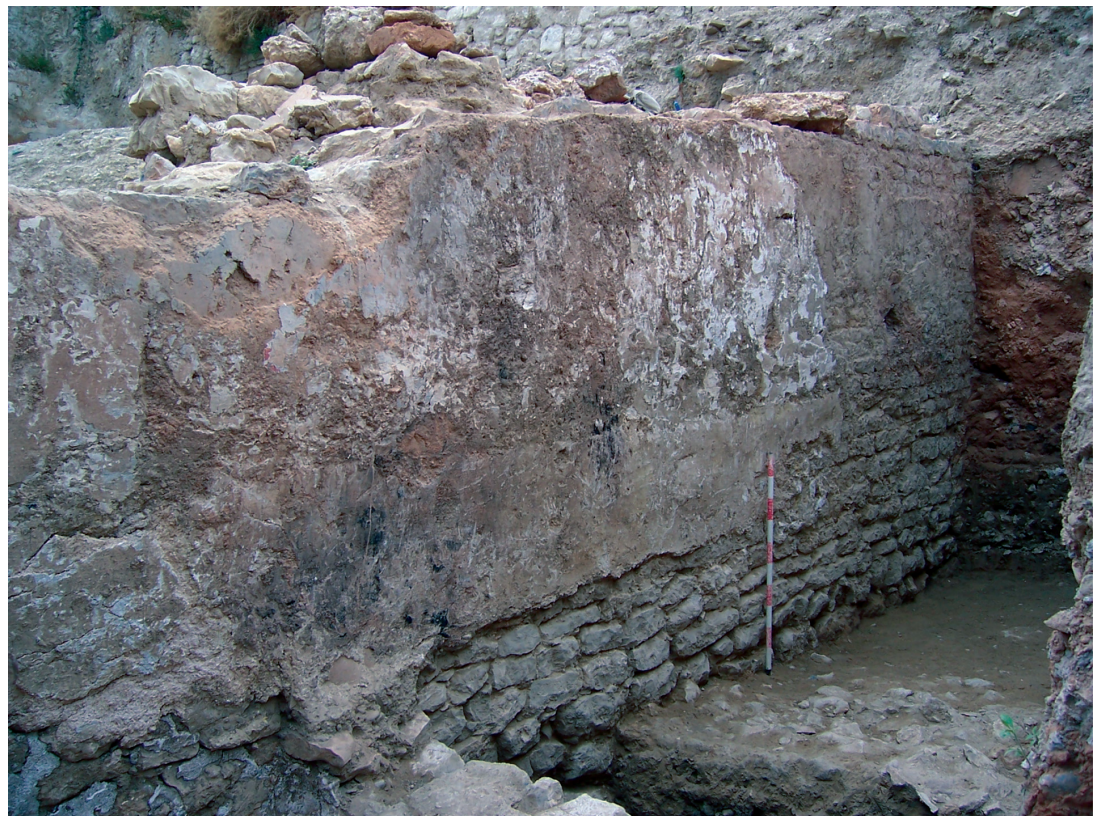

Fig. 5. Muro de época angústea en opus vittatum en la c/ Sant Felip Neri. dencia posiblemente siciliana, pero que de momento per-

manece sin clasificar debido a su singularidad. Aun así, la pieza más destacable es un vaso en forma de cazuela hemisférica, y que cuenta con un vertedor. Es una producción en sigillata africana A, pero de la que no se conocen paralelos en ninguna de las tipologías existentes. Hay que situar el conjunto en un horizonte amplio entre la segunda mitad del s. II d.
C. e inicios del III d. C., que es cuando se data el abandono del edificio. También se han recuperado varios enseres metálicos singulares, entre los que destaca un estrígilo de hierro, muy bien conservado, de sección curva y con el mango doblado y soldado por su extremo al cuerpo de la pieza. Entre los escombros que rellenaban este espacio destacan una serie de
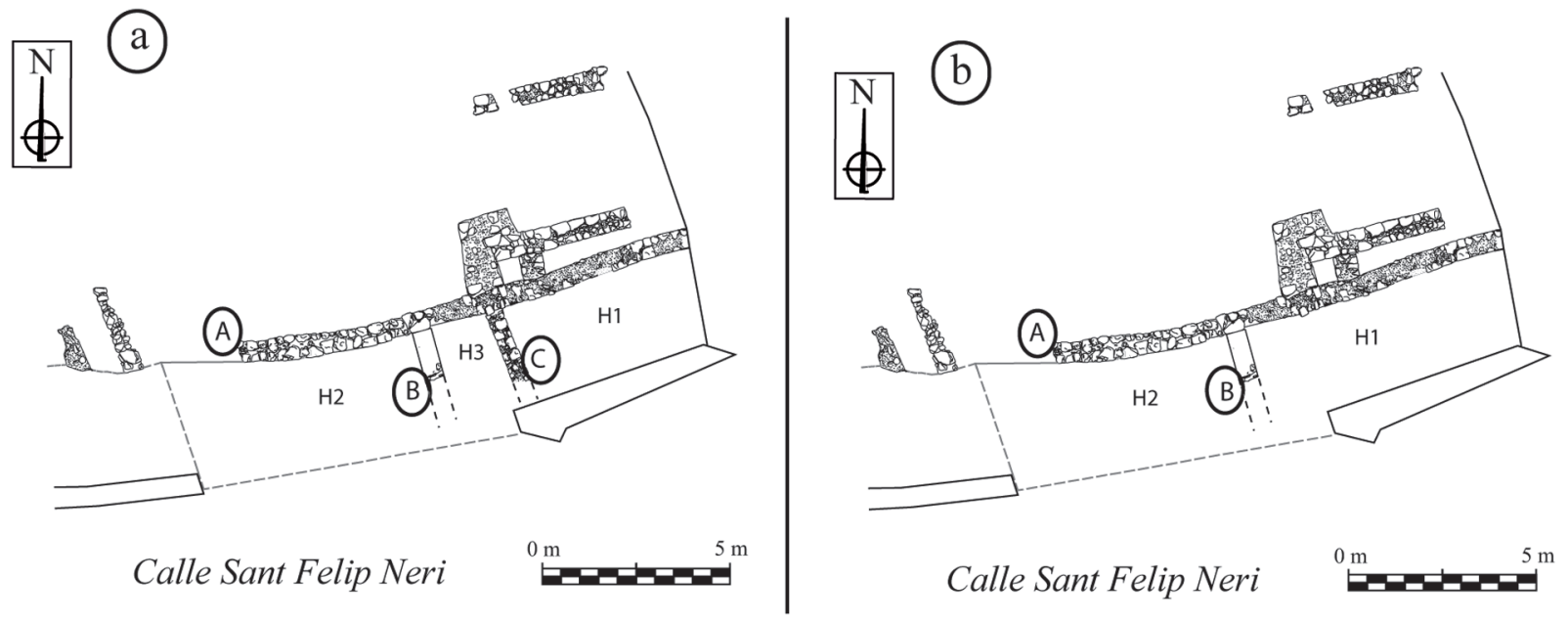

Fig. 6. Planta de la intervención efectuada en la c/ Sant Felip Neri, con detalle de la evolución ocupacional del sector. 


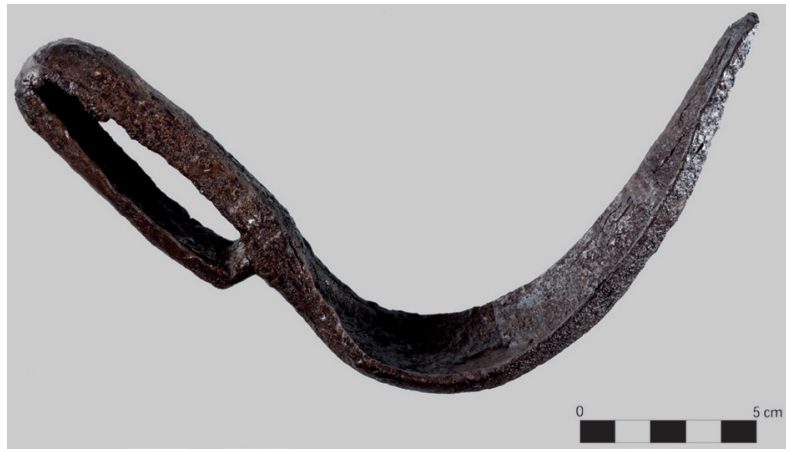

FIG. 7. Estrígilo de hierro recuperado en la intervención de Sant Felip.

fragmentos de mosaico pertenecientes a una misma composición, formada por motivos geométricos en negro sobre un fondo de teselas blancas, que hubo de caer desde una posición elevada, quizás como consecuencia de un desprendimiento procedente de alguna de las terrazas superiores. Aparte de la presencia del estrígilo, que podría apuntar a la posible existencia de una zona de baños en este edificio, no es posible interpretar su naturaleza funcional, más allá del probable carácter de los espacios $\mathrm{H} 1$ y $\mathrm{H} 2$ como zona de almacén, como mínimo en su segunda fase. Sea como fuere, más allá de la interpretación del uso del edificio, se constata la existencia de dos plataformas constructivas distintas, situadas en cotas de aproximadamente $12,80 \mathrm{msnm}$ la superior y $10,20 \mathrm{msnm}$ la inferior, separadas por un notable muro de aterrazamiento ya de época augústea.

\subsection{Intervenciones en las inmediaciones de la cl de la Mercè}

Las excavaciones llevadas a cabo en 2010 en el solar contiguo a Sant Felip Neri, ubicado en la c/ de la Mercè, también permitieron localizar una serie de estructuras murales romanas, si bien su estado de conservación no era tan bueno como en Sant Felip. Las limitaciones impuestas por los promotores de la obra provocaron que las fases más antiguas fueran objeto de un estudio bastante superficial, a pesar de lo cual se recuperaron tres pequeños conjuntos murales atribuibles al s. I d. C. (c1, c2 y c3), de los cuales c1 y c2 son simples agrupaciones de muros de encofrado de 48-50 cm de grosor que forman ángulos

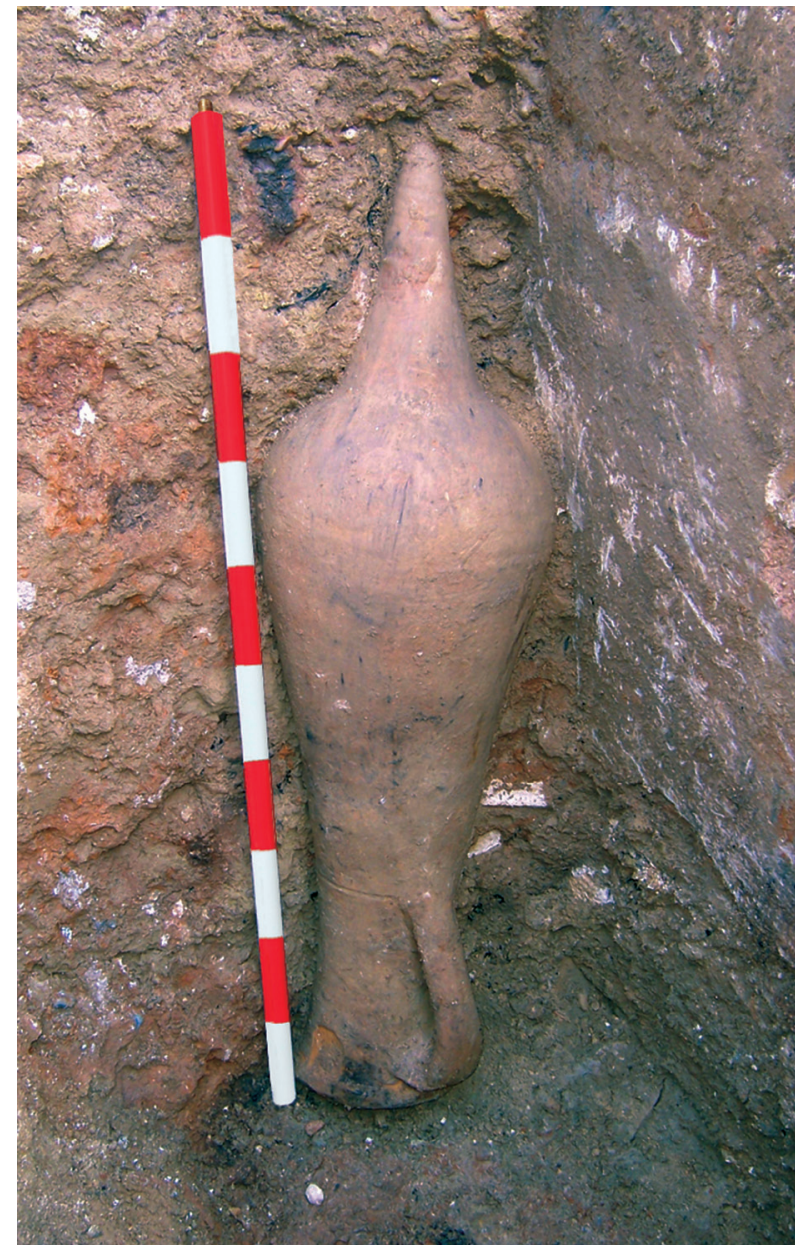

FIg. 8. Ánfora romana Beltrán IIB.

rectos entre sí integrados en complejos mayores que no pudieron ser excavados. El origen de estos restos se puede situar en la segunda mitad del s. I d. C. por la presencia de sigillata itálica de la forma Conspectus 21.3, y las primeras producciones africanas de cocina. Debemos señalar que la orientación de estos muros está en relación directa con el cauce del barranco, respecto al cual se disponen en paralelo o en perpendicular. El carácter segmentario de estos restos que, como se ha indicado, están bastante separados los unos de los otros, así como el hecho que no haya sido posible excavarlos en su totalidad, hacen imposible aventurar una interpretación funcional.

A $8 \mathrm{~m}$ hacia el $\mathrm{E}$ del segundo conjunto apareció un tercero [c3] formado por dos muros de encofrado 
formando un ángulo recto, de los que uno mide más de $7 \mathrm{~m}$ de largo por $40-45 \mathrm{~cm}$ de anchura, dispuesto en sentido E-O, perdiéndose uno de los extremos por debajo del corte de la excavación. De hecho, este muro ya se había documentado en una intervención anterior efectuada en 2003. También se exhumó una esquina y parte de la estructura con la que forma ángulo, con unas dimensiones visibles de $2,5 \mathrm{~m}$ de longitud por $50 \mathrm{~cm}$ de anchura, así como el fondo de la estructura. Su alineación coincide con la de los otros dos conjuntos. En este caso parece claro que

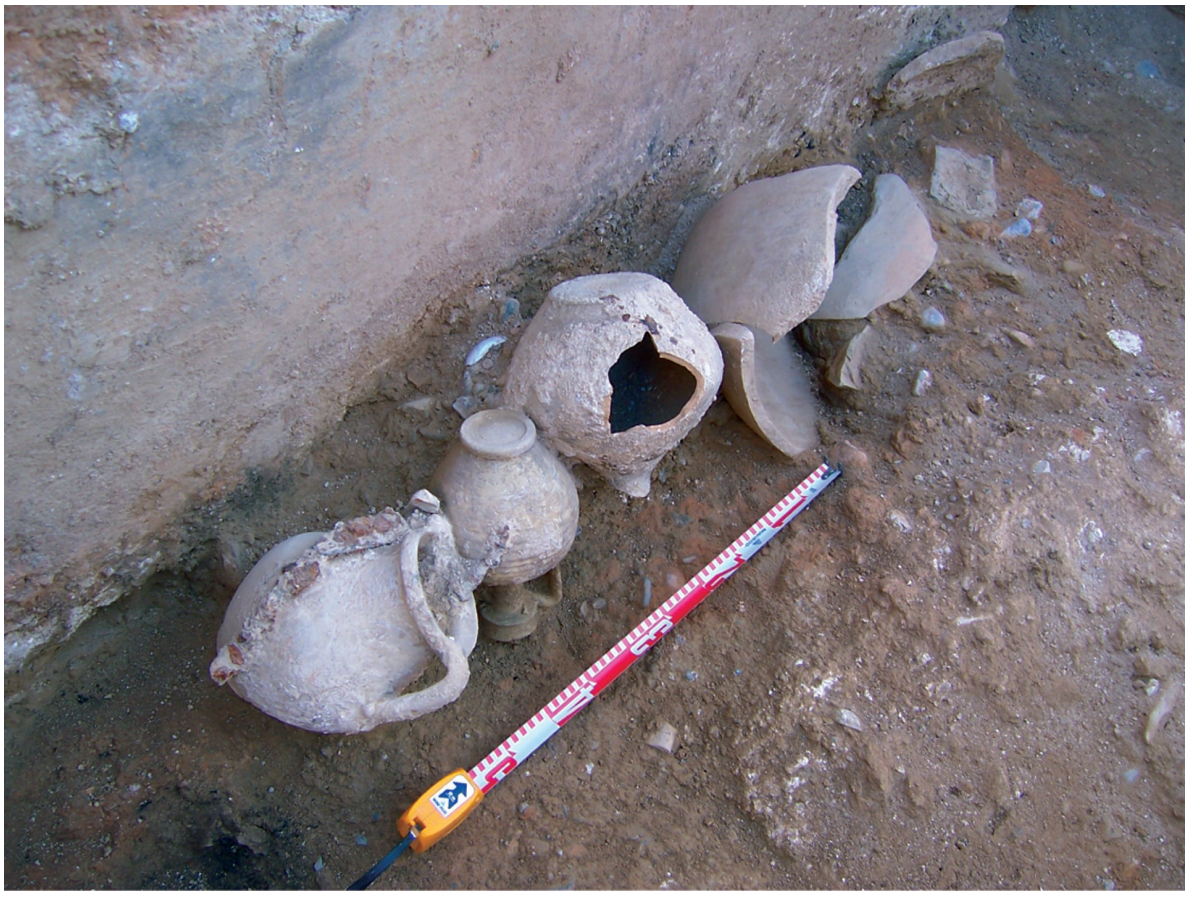

Fig. 9. Piezas intactas de cerámica halladas in situ en la c/ Sant Felip Neri. se trata de un gran depósito de agua -un lacus-, con un acabado en forma de media cańa en el fondo de su cara interna. Cronológicamente no coincidió, o lo hizo en un breve periodo de tiempo, con el de c1 y, de hecho, la vida activa de este depósito no parece haber sido muy larga, puesto que se construyó durante el primer cuarto del s. I d. C., tal y como lo indica el registro cerámico, con abundancia de sigillatas itálicas y cerámica de rojo interno pompeyano, entre otros elementos contemporáneos, y parece que ya en la segunda mitad de la misma centuria estaba amortizado y cubierto. La inutilización del lacus culminó en una intervención antrópica que condujo a un aumento de cota de la superficie de uso de la plataforma, después de que el conjunto conociera un episodio de destrucción con incendio.

Aparentemente los tres complejos se apoyan sobre una misma plataforma constructiva, que habría sido constituida por encima de un aterrazamiento anterior, indicado por los restos de dos muros documentados parcialmente bajo los conjuntos c1 y c2. La similitud en cuanto a técnica constructiva, anchura y trayectoria, hace plausible que se trate de un mismo muro, del que sólo se habrían dejado al descubierto

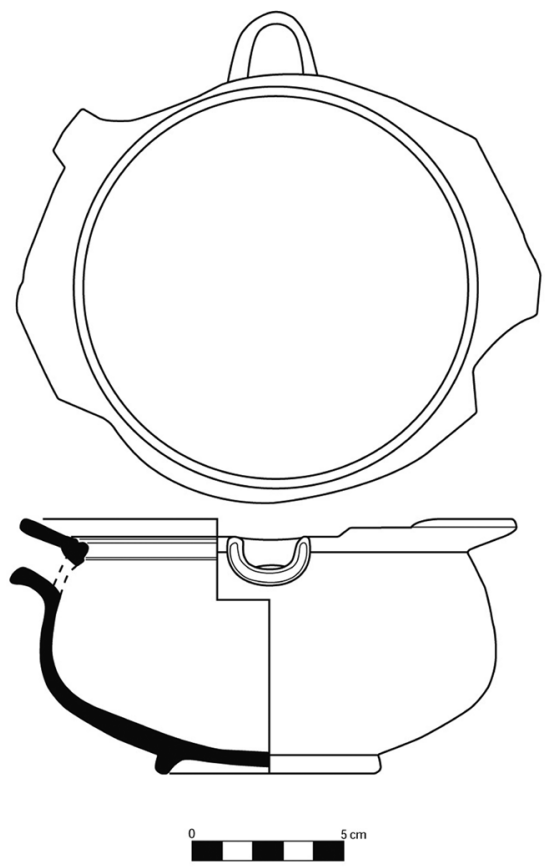

Fig. 10. Forma inédita en sigillata africana $A$ de vaso con vertedor. 


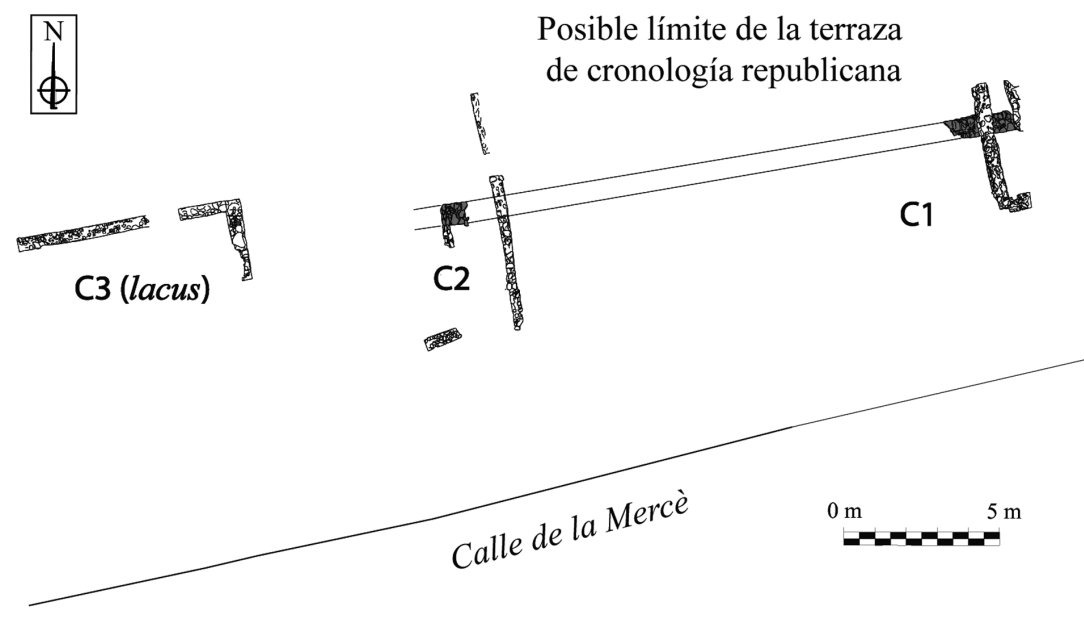

FIG. 11. Planta de las estructuras romanas localizadas en la cl de la Mercè.

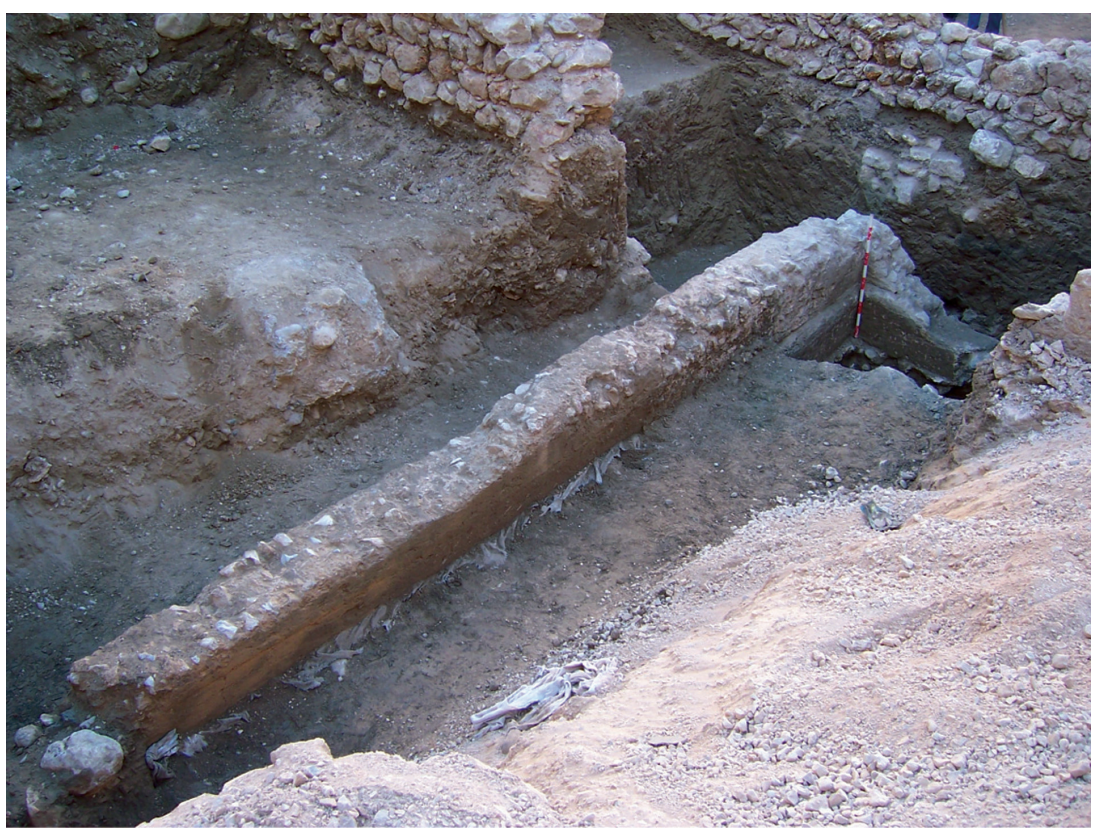

FIg. 12. Lacus del s. I d. C. en la cl de la Mercè. del límite de una amplia terraza que se habría prolongado a lo largo de decenas de metros, ampliada más tarde en profundidad para poder construir los edificios correspondientes a los tres conjuntos arquitectónicos reseñados. Dado que no ha sido posible excavarlo del todo su cronología es incierta, y dadas las relaciones estratigráficas con las otras estructuras y factores como el carácter rústico de su técnica constructiva no puede descartarse que date de época republicana/tardoibérica.

A escasos metros de estos restos, una pequeña excavación efectuada en 2008 permitió descubrir otro muro bajo la cripta de la iglesia de la Reparació, donde el arquitecto J. Abril (1931) localizó numerosos restos de entierros tardorromanos a principios del s. xx. Este muro, situado por debajo de la cota en la que Abril encontró las inhumaciones, está levantado en paramento de sillarejo, y por lo tanto es similar a los ya conocidos en Sant Felip Neri. Está orientado en perpendicular al barranco, y se conoce en una longitud de menos de $1 \mathrm{~m}$, debido a la modestia de los trabajos. En cuanto a su cronología, parece que se le adosaban estratos de los ss. I y II d. C. La cota en la que apareció es bastante baja, unos $5 \mathrm{msnm}$, de modo que debe de tratarse de una construcción realizada sobre el mismo lecho del barranco. dos segmentos separados entre ellos por $18 \mathrm{~m}$ de distancia. Se trata de una construcción de piedras de medianas dimensiones sin escuadrar y unidas con barro, con una anchura de $70 / 80 \mathrm{~cm}$. En un punto de su trazado se ha localizado una estructura que se le apoya, construida según la misma técnica, pero conservada muy parcialmente. Probablemente se trata

\subsection{Intervenciones en la c/ Montcada}

Entre 2006 y 2010 se efectuaron diversos trabajos arqueológicos en la calle Montcada (Diloli et al., 2010), que en sus niveles más antiguos han permitido 
localizar al menos un gran edificio construido a mediados o en la segunda mitad del s. I d. C. con ciertas peculiaridades reseñables. En una primera fase hallamos 6 sillares de diferentes dimensiones y con toda seguridad reutilizados -dado que no hay dos con las mismas dimensiones ni la misma forma-, colocados encima de pequeñas bases de mortero de escasa entidad situadas a distancias regulares: 6,60 m de E-O y 8,40 m de N-S. Estos sillares van descendiendo de nivel de forma progresiva hacia el lecho del barranco, con un desnivel acumulado de 1,30 $\mathrm{m}$ entre el punto más elevado y el sillar inferior $-6,45-5,15$ msnm-. A pesar de que la presencia del nivel freático dificultó

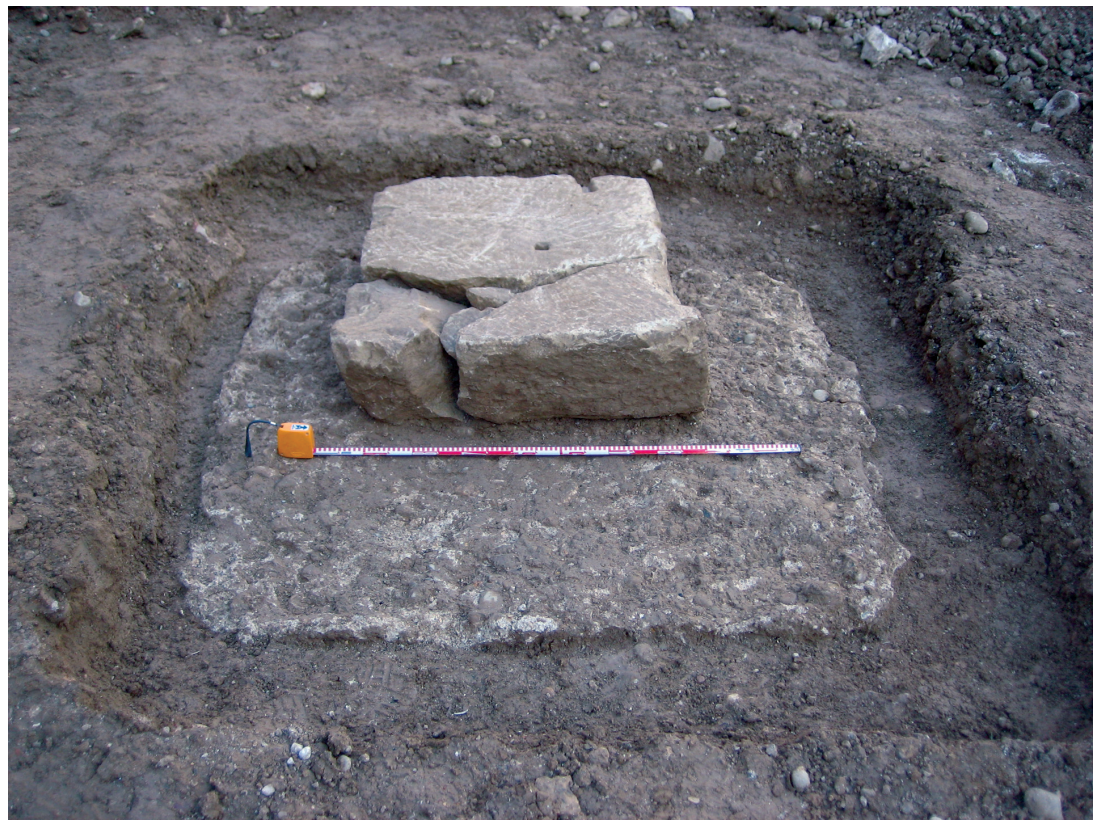

FIG. 13. Detalle de uno de los sillares alineados de la c/ Montcada. un desarrollo óptimo de los tra-

bajos, tanto las distancias entre los sillares como la disposición topográfica de los mismos inducen a pensar que se trata de un gran edificio porticado. Teniendo en cuenta la poca potencia de las bases de mortero y la inestabilidad del terreno, el alzado de este edificio no podía contar con elementos arquitectónicos muy pesados, lo que excluye el uso de materiales pétreos. Los sillares funcionarían como basamentos de pilares de madera sobre los que se extendería una estructura en material perecedero, mientras que la pavimentación probablemente sería de tierra batida o de madera y sobreelevada del suelo.

La segunda fase consta de una serie de 7 muros de encofrado de hormigón, con unas medidas de entre 3 y $10 \mathrm{~m}$ de longitud por unos $50 \mathrm{~cm}$ de anchura, situados a una cota similar a la de los sillares. Desgraciadamente en la mayor parte de los casos sólo se conservan a nivel de cimentación. Con todo, tanto sus dimensiones como su disposición, con muros perpendiculares entre ellos que definen posibles ámbitos más o menos rectangulares, suponen una radical reforma del primer edificio porticado, pues las relaciones estratigráficas muestran que los muros se construyeron con posterioridad a los sillares sin que parezca posible una coexistencia de los dos proyectos, de forma que el primer edificio tuvo que ser completamente desmantelado antes de construir el segundo.

Tanto en la primera fase como en la segunda, la orientación de las estructuras es en sentido NO-SE. Debemos apuntar que no se ha encontrado ninguna evidencia de pavimentaciones para la segunda fase, de forma que la localización de una gran cantidad de fragmentos de opus signinum en la misma cota en la que se apoyan las cimentaciones de los muros podría estar indicando el tipo de suelo de estos espacios, que también pudieron haber sido sencillamente de tierra, mientras que en la primera fase cabe imaginar la existencia de un tabulatum de madera, elevado del suelo. Tanto los muros como los sillares presentan una cronología romana altoimperial, aunque los condicionantes de la excavación dificultan formular una datación con un alto grado de precisión. La segunda fase del edificio parece poder situarse ya en el s. II d. C. El conjunto cerámico comprende varios elementos de vajilla fina y está caracterizado por producciones de sigillata sudgálica (formas Drag. 15/17, 18, 29/37 y Ritt. 8) e hispánica (formas Drag. 27, 24/25, 29, 37). La ausencia de sigillatas africanas podría sugerir una datación todavía dentro del s. I d. C., pero el hecho de que la fase constructiva se concrete ya en aquellos momentos induce a datar la segunda fase en un momento algo más tardío. 


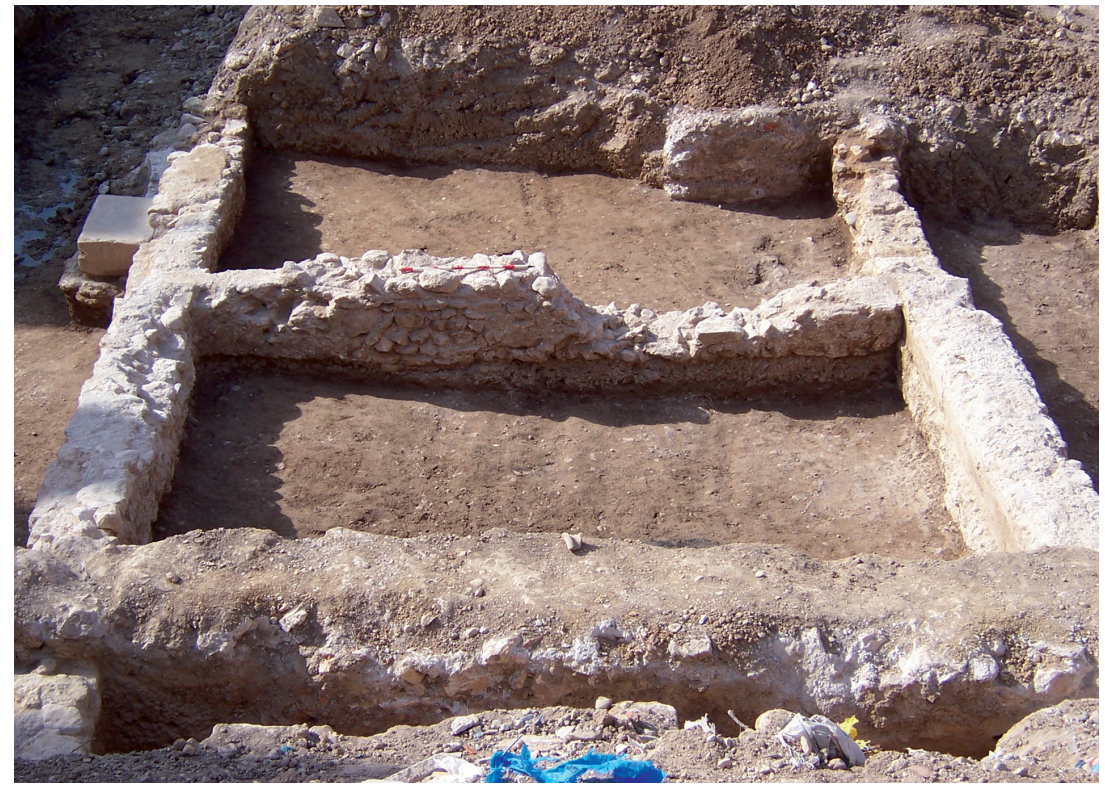

Fig. 14. Estructuras pertenecientes a la segunda fase de ocupación de la c/ Montcada. se le apoya, y del que parten por lo menos dos muros más, todos ellos levantados con piedras sin escuadrar unidas con barro. La cronología de este pequeño grupo constructivo, amortizado en época altoimperial, plantea ciertas dudas. Se cimenta en estratos análogos a los que indican la acumulación de desechos en el pie de la fortificación ibérica, ricos en cerámica ibérica de datación poco precisa, con la presencia de algunos fragmentos de ánfora itálica, uno de los cuales, perteneciente a una Lamb. 2, ya sería indicativo del s. I a. C. en caso de que se considerase con valor conclusivo.

Por otro lado, ya se ha comentado la existencia en la c/ la Mercè de dos segmentos de un muro, posiblemente pertenecientes a la misma estructura,

\section{Posible ocupación del Rastre en época tardoibérica/romana republicana. ¿Una ampliación del núcleo protohistórico?}

La ocupación del espacio durante el periodo republicano no ha sido todavía corroborada con total seguridad, si bien hay varios indicios que apuntan en este sentido. De entrada se constata, como ya se ha visto, la existencia de al menos un aterrazamiento -de función defensivaen la ladera de la Zuda en época ibérica, detectado en la c/ Sant Domènech. La posible continuidad del uso de esta fortificación a lo largo de los ss. II y I a. C. es por ahora desconocida, no obstante los indicios apuntan a que perdería parte de su funcionalidad antes de época imperial. En la intervención que permitió su descubrimiento también se localizó un muro de dimensiones más modestas -unos $60 \mathrm{~cm}$ de anchura- que

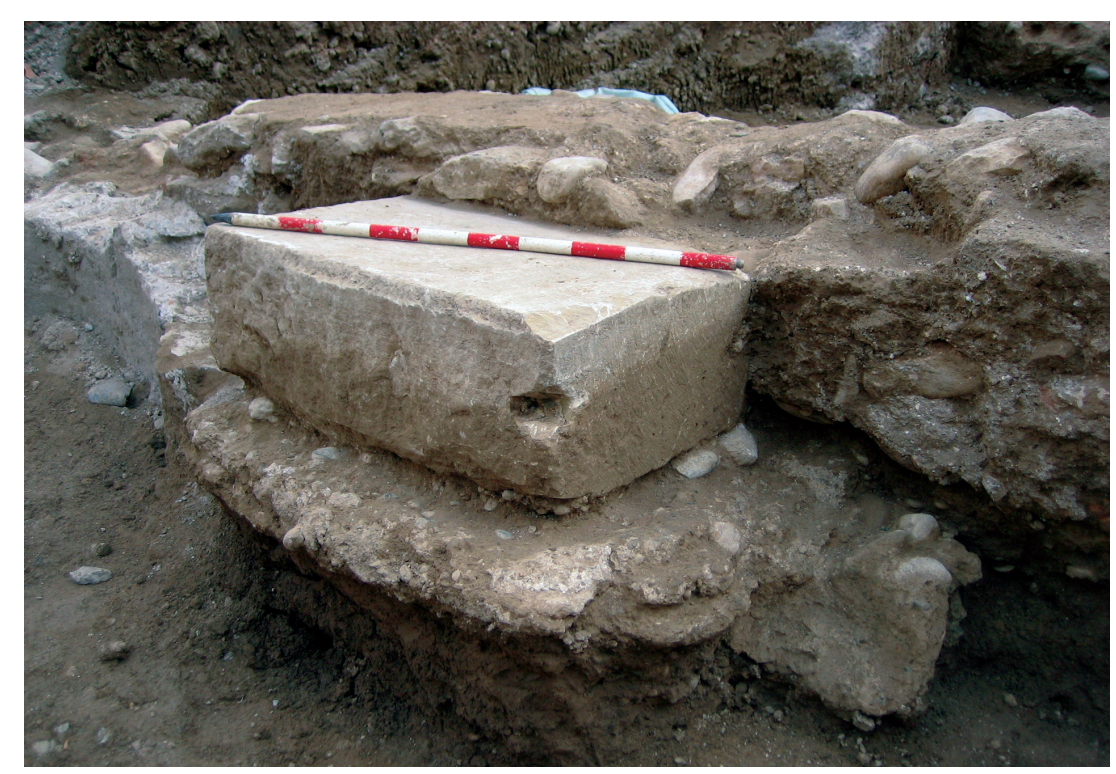

Fig. 15. Detalle de la estratigrafía constructiva en la c/ Montcada. amortizado por las posteriores construcciones altoimperiales y levantado con la misma técnica constructiva que los muros de la c/ Sant Domènech. La imposibilidad impuesta por fuerzas externas para estudiarlo con atención impide aventurar una datación fiable, pero la 
evidencia de estructuras del s. I d. C. que lo cubren, construidas con posterioridad a su amortización, apuntan a una datación anterior al cambio de era.

A estos muros de cronología incierta hay que añadir la presencia de unidades estratigráficas aisladas, bastante alteradas, y sin relación directa con ninguna estructura, pero con un contenido de restos de cerámica ibérica y de procedencia itálica republicana bastante coherente, que parece indicar un horizonte de la primera mitad del s. I a. C. En Sant Felip Neri, por ejemplo, se documenta una pre-sencia significativa de cerámica ibérica, predominando los cálatos y las tinajas de tipo Ilduradin como piezas más representativas. A estas producciones cerámicas, que se sitúan a partir del s. II a. C., se les añade una cierta cantidad de barnices negros, entre los que predomina la cerámica de barniz negro del Círculo de la в. Este mismo tipo de materiales aparece fuera de contexto con una cierta frecuencia en las intervenciones efectuadas en el entorno de la Zuda, hasta el punto de que es difícil concretar si están en posición secundaria, provenientes
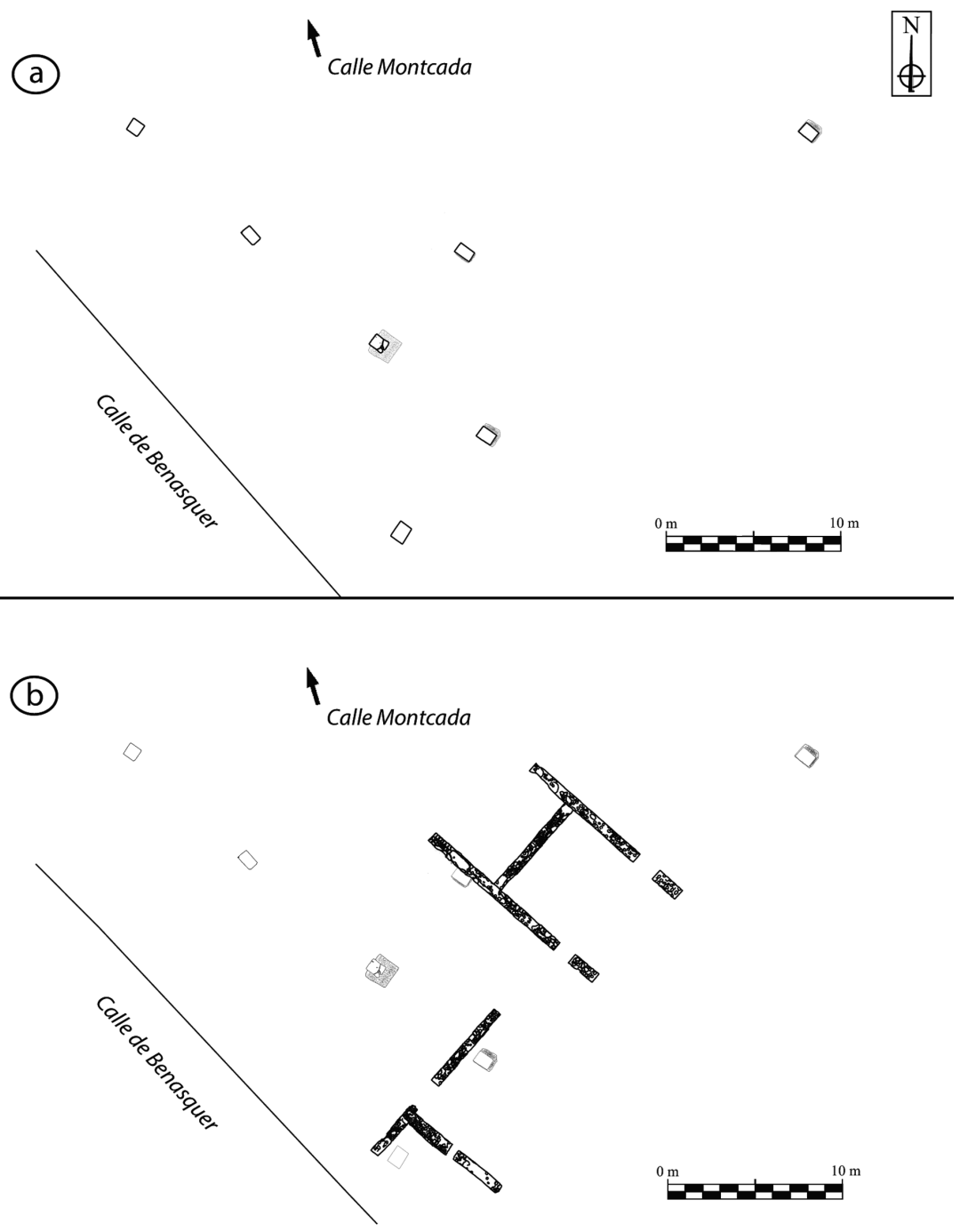

FIG. 16. Planta de las estructuras romanas recuperadas en la c/ Montcada: a) primera fase y b) segunda fase.

de la parte superior del cerro, o

si en realidad forman parte de una primitiva formación de terrazas constructivas, anterior a los aterrazamientos emprendidos a partir de época augústea.

Es interesante apuntar que fue en la c/ de la Mercè, justo en la zona estudiada, donde en el s. Xvi se recuperó un tesorillo de monedas de plata procedentes de cecas próximas a César durante las guerras civiles (Campo, 1984; Járrega, 2006), lo que viene a reforzar la idea de la existencia de construcciones en sus inmediaciones ya en el s. I a. C. Por ello no se puede descartar que esta primitiva formación de terrazas

constructivas se pueda relacionar con la fundación romana de la ciudad y, a fortiori, con la concesión del estatus municipal por parte de César, e incluso con la aparición del mismo topónimo Dertosa, desconocido antes de la época imperial.

\section{Abandono del suburbio}

En ninguna de las intervenciones efectuadas en el barranco del Rastre y en la ladera meridional de 
la Zuda hay constancia clara de una continuidad del hábitat a partir del 200 d. C. -entendiendo esta fecha como referente con un cierto margen temporal-. Los restos de Sant Domènech aparecen cubiertos por una capa de sedimento acompañada por numerosos restos entre los que destacan fragmentos de estuco pintado, opus caementicium, fracciones de mosaico y materiales cerámicos que en ningún caso sobrepasan esta fecha. El lugar en el que se han podido estudiar en mejores condiciones estos momentos finales ha sido en Sant Felip Neri, donde las piezas de cerámica han sido recuperadas en un excelente estado de conservación, asociadas también a restos de materiales de construcción. Con todo, estos objetos no aportan una cronología especialmente precisa, de forma que sólo permiten corroborar este intervalo de entre finales del s. II d. C. y principios del III d. C., lo que podría concordar con el final de la fase 2 de Montcada, si bien no se puede descartar que esta última se prolongase todavía por algún tiempo. Lo que sigue a continuación son prácticamente dos siglos de vacío de información que acaba a finales del s. Iv d. C., cuando se producen las primeras inhumaciones en el mismo sector del edificio de la c/ Montcada, hecho también constatado a partir de este momento y durante los dos siglos siguientes en los márgenes de la mayor parte del barranco y en la ladera sur de la $\mathrm{Zuda}^{3}$. A finales del s. Iv d. C. el edificio de la fase 2 de Montcada está arrasado y en algunos casos las tumbas recortan parte de la cimentación de las estructuras precedentes. En todo el sector sólo se conocen restos no funerarios de cierta entidad en la zona cercana a la catedral, en la plaza del Ábside y en la plaza de l'Olivera, donde se localizaron varios muros datados entre los ss. vi y viII d. C. que denotan una cierta complejidad constructiva. En la c/ de la Mercè apareció un segmento de muro de factura muy grosera, con piedras sin escuadrar unidas con barro, que también tiene que incluirse en este periodo, a pesar de que en este caso se trataría de una estructura probablemente relacionada con un complejo funerario del s. vi.

En las excavaciones de la plaza del Ábside, la posible presencia de estructuras altoimperiales -no explicitadas como tales por parte de sus excavadores,

3 Navarro, S.: Les necròpolis romanes de Dertosa (Tortosa, Baix Ebre). Trabajo de Investigación inédito presentado en 2008 en el Máster Interuniversitario en Arqueología Clásica URV-UAB-ICAC.

(C) Universidad de Salamanca
Griñó y Camarasa (2011) - también conoce un final más o menos abrupto, como se puede deducir de la amortización de un posible depósito, que parece coincidir con un horizonte del 200 d. C. En este caso, un potente muro de más de un metro de anchura levantado sobre los restos confirma la continuidad posterior del hábitat en este lugar, situado posiblemente intramuros.

En el actual estado de la investigación parece claro que una reforma urbanística de gran envergadura puso punto y final a la ocupación de este barrio suburbano. Ahora bien, los motivos del abandono no están nada claros. La incursión franca del 260 es demasiado tardía para explicarlo, si es que llegó a afectar a Dertosa, puesto que, además, hasta ahora no se conoce ningún indicio de destrucción violenta que pueda situarse claramente durante este periodo. El hecho político que a nivel temporal concuerda mejor con el abandono del área es la victoria de Septimio Severo sobre Clodio Albino, en 197. Es verosímil que la represión contra los numerosos partidarios que Albino tenía en esta provincia contribuyera a los problemas internos de la sociedad dertosense, a pesar de que sería muy complejo atribuir sólo a este hecho la desaparición física de un barrio entero. Por otra parte, otros documentos reflejan las dificultades que atravesaba la ciudad en estos momentos, como la legación que Dertosa envió a Antonino Pio, indicando una situación de cierta gravedad ya a mediados del s. II d. C. (Genera y Járrega, 2009). Los problemas documentados durante este periodo no son exclusivos de este municipio. Parece ser que en Tarraco, quizás en el marco de la represión llevada a término en 197 por parte de Septimio Severo contra Novio Rufo, el gobernador provincial que se declaró partidario de Clodio Albino, rival de Severo en su pugna por el trono imperial, hubo importantes cambios que podrían explicar varias amortizaciones en el área portuaria y suburbial de la ciudad, además de la desaparición de algunos establecimientos rurales (Járrega, 2008). Este proceso culminaría en el abandono total del suburbio y su sustitución por una extensa necrópolis tardoantigua (Del Amo, 1979; López Vilar, 2006). No sabemos si este proceso fue provocado o precipitado por la guerra civil entre Septimio Severo y Clodio Albino o si se inició con anterioridad y se tendría que atribuir a otras causas, que podrían estar relacionadas con las que causaron el abandono del suburbio meridional de Dertosa. 


\section{Reconstrucción de un perfil topográfico: un urbanismo periurbano escalonado}

Si encuadramos los datos arqueológicos expuestos en un perfil topográfico del barranco podemos extraer algunos datos importantes respecto a la ubicación de las construcciones. En primer lugar debemos apuntar que el espacio más cercano al cauce es un lugar que se evitó en cierta medida, de forma que no conoce la densidad de construcciones que hay en la ladera del monte de la Zuda. Los restos más cercanos al cauce corresponden al edificio de la cl Montcada, en una situación ya en ascenso hacia la ladera del Sitjar, acompañados por algunos restos segmentarios de muros, como los conocidos a la plaza de l'Olivera y los situados bajo la iglesia de la Reparació, cercanos al arranque de la ladera de la Zuda. Hasta ahora no se ha documentado ningún resto estructural entre los dos conjuntos, lo que refuerza la idea de que la parte inferior permaneció libre de edificaciones durante todo el periodo romano. Los datos actuales sitúan la mayoría de construcciones conocidas entre los 10 y los $15 \mathrm{msnm}$, en una posible primera terraza. Además de la plataforma en la que se ubican los muros de la c/ Montcada, la plaza de
l'Olivera y la iglesia de la Reparació, se pone en evidencia la existencia de por lo menos tres terrazas constructivas más. La primera se sitúa entre el muro ubicado en el interior de la iglesia de la Reparació y los conjuntos arquitectónicos en encofrado existentes en la calle de la Mercè; la segunda entre

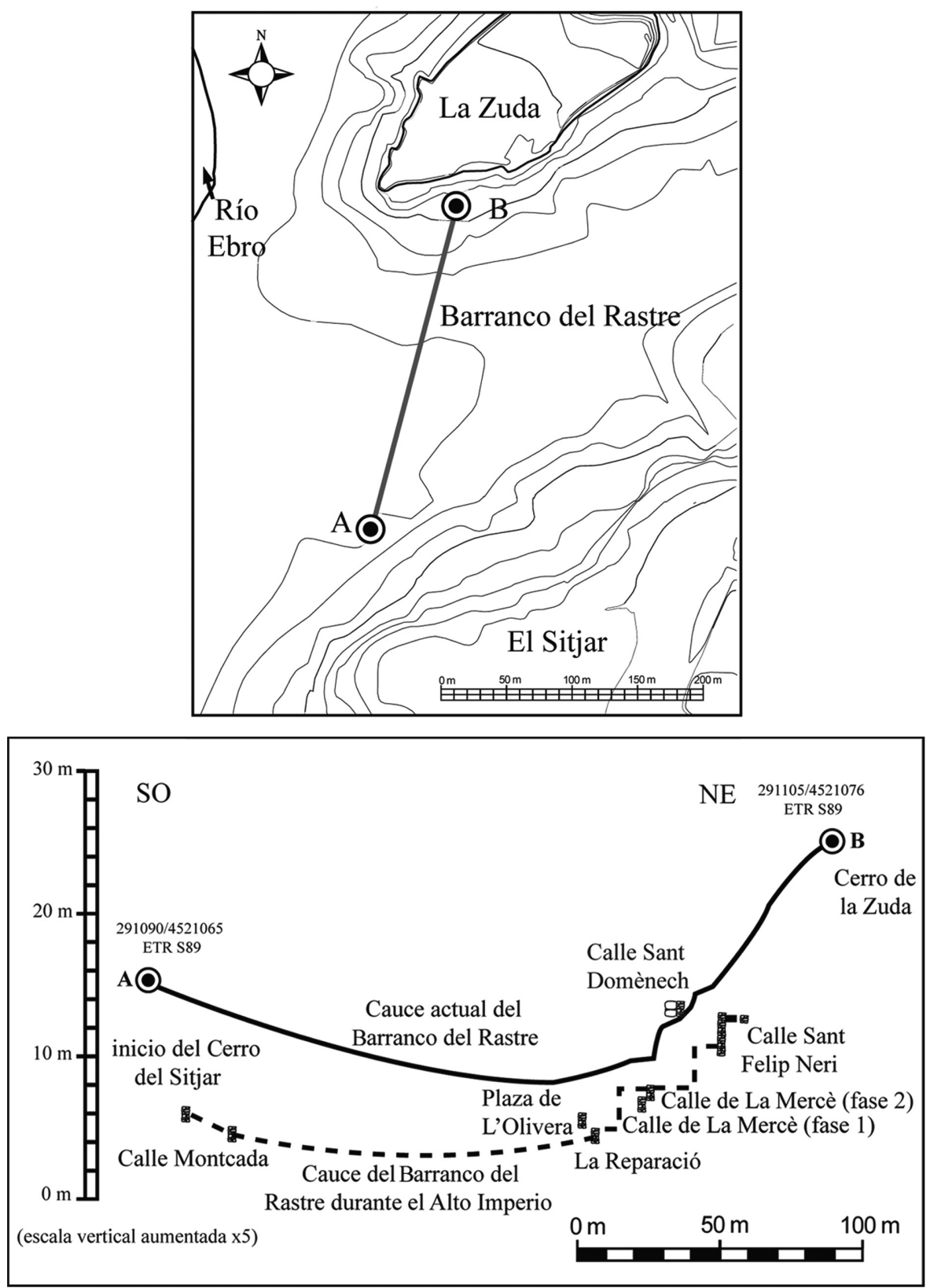

Fig. 17. Reconstrucción del perfil topográfico del barranco del Rastre con la localización de los restos romanos conservados. 


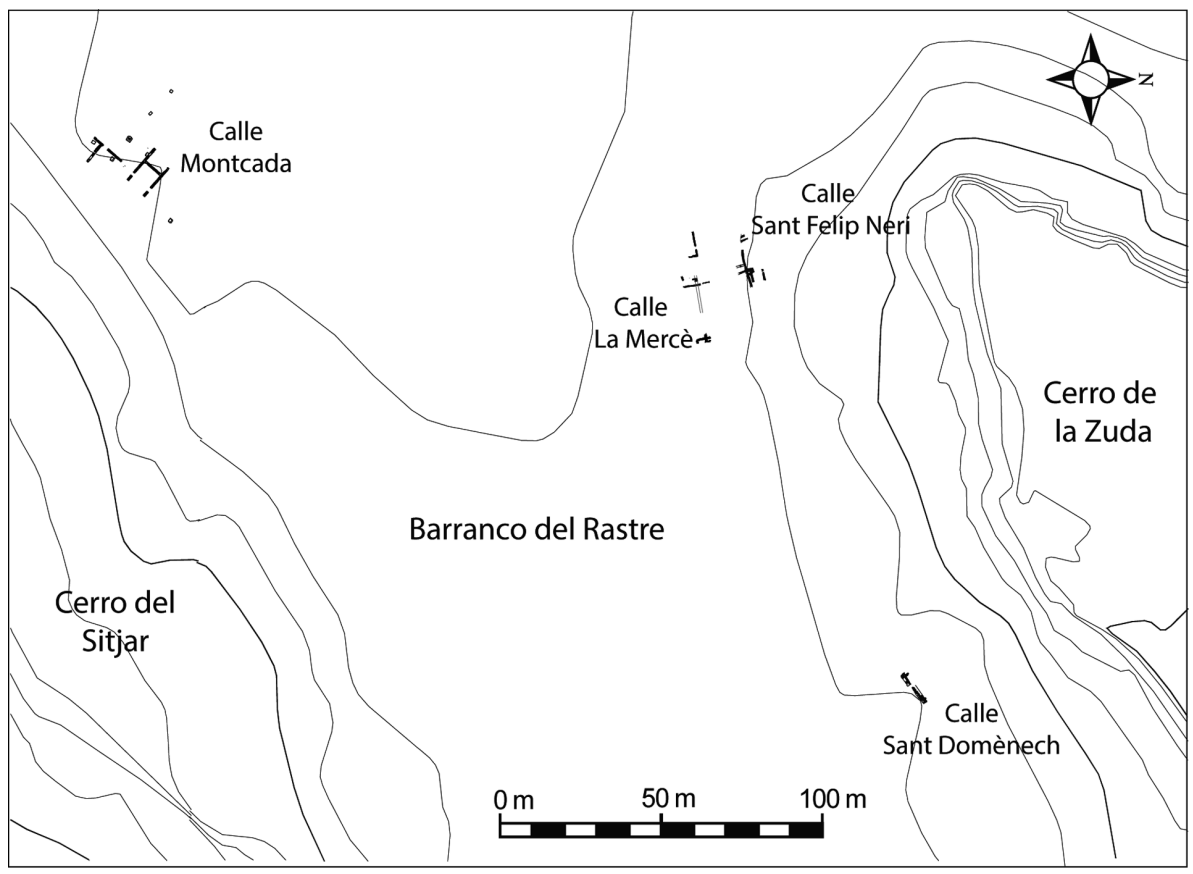

Fig. 18. Planta general de las estructuras romanas recuperadas ubicadas sobre la topografía urbana de este sector de la ciudad de Tortosa.

estos conjuntos y la plataforma inferior de la c/ Sant Felip Neri, y la tercera se corresponde con la plataforma superior documentada en la misma c/ Sant Felip Neri. A partir de este esquema se observa que hay muros de aterrazamiento que todavía no han aportado datos arqueológicos y que explicarían los notables desniveles existentes entre el muro de la iglesia de la Reparació y el conjunto de la c/ la Mercè y entre este último y el de Sant Felip Neri. Este urbanismo escalonado podría haberse extendido hasta la parte superior de la Zuda, donde de momento no se han efectuado intervenciones que hayan aportado datos significativos. A diferencia del fondo del barranco, en la ladera del cerro hay una densidad ciertamente importante de edificaciones, que se levantan sobre plataformas artificiales de entre 20 y $30 \mathrm{~m}$ de profundidad. El panorama representado en este esquema corresponde al s. I d. C., y pensamos que en parte ya era así en el periodo augústeo, como mínimo. Ahora bien, se entrevé la existencia de una organización del espacio más antigua, de la que son testigos los muros de datación dudosa localizados en la c/ Sant Domènech y en la iglesia de la Reparació, sin contar con una posible ocupación anterior, prerromana.
De esta forma, los aún insuficientes indicios del poblamiento de época republicana/tardoibérica del sector parecen apuntar a un horizonte de la primera mitad del s. I a. C., lo que podría relacionarse con el fenómeno de fundación de ciudades romanas de nueva planta en todo el actual territorio de Cataluña en la misma época, como Iluro, Baetulo, Ampurias romana, Iesso, Aeso (Guitart, 2006，2010), Gerunda (Burch et al., 2000; Nolla, 2006), etc. En realidad, el escalonamiento sistemático de toda una montańa empleado como solución urbanística de gran envergadura -asumiendo la existencia de importantes aterrazamientos en Baetulo o las soluciones empleadas para salvar el complicado relieve de Gerun$d a$, etc.- está muy alejado de estos ejemplos ex novo, levantados todos ellos en un lugar preestablecido y con un diseño fruto de una mentalidad puramente romana. Tampoco parece comparable con el modelo de terrazas escalonadas monumentales de inspiración helenística, al estilo de Tarraco. Por otro lado, Celsa, a pesar de estar levantada sobre una ladera aterrazada sobre el Ebro, despliega un urbanismo reticulado de estilo itálico (Beltrán-Lloris et al., 1984), todavía no documentado en Dertosa, donde no es descartable. Lo que se conoce hasta ahora del caso tortosino, con la carencia que significa no tener datos del actual barrio de Remolinos, que por sus características orográficas podría contar con un trazado urbano sensiblemente diferente al descrito para el entorno de la Zuda, parece mucho más cercano a aquellos casos de ciudades romanas, o 'romanizadas', que parten de un importante precedente prerromano ubicado en altura, a partir del que se va extendiendo la nueva ciudad, con más o menos dificultades de adaptación al terreno, como Bilbilis (Martín Bueno, 1975, 2000) o incluso en cierta medida Carthago Nova (Martín, 
1995-96). En el caso de Labitolosa se trata de un núcleo fundado por peregrini romanizados, pero procedentes de los alrededores (Chasseigne et al., 2006; Magallón y Navarro, 2010). Quizás los ejemplos más cercanos sean Saguntum, donde la planificación urbanística romana tiene el oppidum de Arse como punto inicial sobre el monte del Castillo (Aranegui, 2004, 2006), e Ilerda, en donde se ha observado un sistema de terrazas atribuido, como en Dertosa, a una zona extramuros situada en la ladera del cerro -denominado también Zuda-, en el que posiblemente se sitúa el núcleo ibérico de Iltirta (Payà et al., 2000; Pérez Almoguera, 1991).

\section{Recapitulación}

La abundancia de restos constructivos altoimperiales descubiertos durante los últimos años en el área del Rastre no tiene que hacer perder de vista que, como se indicaba al inicio, esta zona estaba lejos de ser el centro urbano de Dertosa. Del trazado del cinturón de murallas que protegía la ciudad se conoce todavía muy poco. No fue hasta el año 2001 cuando una excavación en el aula mayor de la catedral hizo salir a la luz su parte superior en un tramo ínfimo del recorrido original. No obstante, el hallazgo permite adivinar la continuación en dirección este-oeste, explicando en parte la forma irregular del claustro de la catedral, puesto que su ala sur emplea la muralla romana como cimentación. Mientras que en dirección o se dirige al río, en dirección e su trazado sigue siendo una incógnita. Una hipótesis plausible hasta fechas recientes, formulada a principios del s. $\mathrm{xx}$ (Abril, 1931), sugería que podría seguir una curva de nivel de la Zuda, a media altura de la ladera, posiblemente en paralelo y a la altura de las actuales calles de la Mercè, San Felip Neri o del Vall. Con los datos disponibles gracias a las intervenciones arqueológicas aquí expuestas se puede rechazar esta hipótesis puesto que es segura la inexistencia de fortificación romana alguna entre las calles de Sant Felip Neri y Nou del Vall. Tampoco en las excavaciones de la cl Montcada se han localizado restos de muralla, pero este hecho era del todo esperable, puesto que en el espacio comprendido entre las calles Nou del Vall y Montcada nos encontramos justo con el cauce del barranco, la parte más profunda, y por lo tanto el lugar menos indicado para construir una muralla, que quedaría completamente dominada desde la altura superior de la muy cercana colina del Sitjar.

Otra razón que explica el carácter suburbial de la zona es la proliferación de tumbas de inhumación a partir de finales del s. IV d. C. Hasta ahora no se conocen tumbas más antiguas, pero sí varias muestras de epígrafes funerarios altoimperiales - reutilizados en construcciones y sepulcros tardoantiguos-, que sugieren la existencia de sepulcros de los ss. I y II d. C. en un lugar cercano. Dadas las circunstancias, el trazado de la muralla se tendría que buscar en una cota más elevada, siguiendo quizás el recorrido de la c/ Costa de Capellans, ya muy cerca de la parte superior de la Zuda y en la base del castillo medieval. Muy posiblemente la ancha estructura andalusí documentada recientemente en la plaza del Ábside de la catedral, interpretable como una fortificación, y que concordaría con esta dirección, podría estar apoyándose sobre un tramo de la muralla romana (Grinó y Camarasa, 2011). No está de más recordar la cita del geógrafo al-Hymiari (ss. XIII-XIv) según la cual la muralla de época califal se construyó sobre una fortificación más antigua, que no puede ser sino la muralla romana (Járrega, 2006, 2009). Respecto a los límites del suburbio no se puede aventurar todavía ningún dato seguro, más allá de los que imponen los accidentes naturales y lo poco que se conoce respecto al límite amurallado de la ciudad. Por el e el límite máximo estaría en el mismo río Ebro, mientras que por el $\mathrm{N}$ estaría en el trazado de la muralla, bordeando la catedral medieval y seguramente la parte superior de la Zuda. La penetración del área edificada hacia el $\mathrm{E} y$ hacia el $s$ es totalmente desconocida. En la c/ Montcada, el límite sur de la excavación arqueológica alcanza la base del cerro del Sitjar, en un punto en el que se documenta la presencia de estructuras romanas. No hay motivos para pensar que la ladera $\mathrm{N}$ del Sitjar no conociera un fenómeno de urbanización parecida a la de la ladera $s$ de la Zuda durante la misma época, aunque este último extremo no pasa de mera hipótesis dado que se trata de un sector arqueológicamente muy poco conocido. En todo caso las intervenciones realizadas en la parte superior del Sitjar no han permitido documentar hasta ahora muestras de ocupación de época romana.

Por lo que respecta a aspectos funcionales de este suburbio situado alrededor del barranco del Rastre, debemos apuntar que a partir de los años 80 del s. Xx empezó a relacionarse este arroyo intermitente con la 
actividad portuaria de la ciudad (Curto et al., 1986; Miravall, 1988; Barrassetas, 1988). Pensamos que el descubrimiento en la c/ Montcada del almacén porticado - horreum-, dividido en varias naves paralelas, refuerza la idea de una relación estrecha entre el barranco del Rastre y el área portuaria de la ciudad. El abandono del suburbio en torno al $200 \mathrm{~d}$. C. no implicaría el fin de la utilización del puerto, puesto que el flujo de importaciones de todo el Mediterráneo sigue siendo constante a lo largo de los ss. IV, V y VI d. C., como se ha comprobado repetidamente en el curso de las excavaciones.

Las causas de este abandono todavía no están claras. A partir de finales del s. Iv d. C. esta área se convierte en una extensa necrópolis, en un fenómeno paralelo al que se documenta en Tarraco, donde el abandono del suburbio fue seguido del establecimiento de una necrópolis tardoantigua. La ladera meridional de la Zuda no volverá a ser urbanizada plenamente hasta la ocupación musulmana, mientras que, por su parte, el cauce del barranco del Rastre no lo será hasta los ss. X-XI.

\section{Bibliografía}

Abril, J. (1931): Un capitol de la meva actuació a Tortosa. Tortosa.

Aranegui, C. (2004): Sagunto. Oppidum, emporio y municipio romano. Barcelona: Ed. Bellaterra.

Aranegui, C. (2006): "From Arse to Saguntum". En Abad, L.; Keay, S. y Ramallo, S. (eds.): Early Roman towns in Hispania Tarraconensis. Portsmouth, pp. 63-74.

ArbeloA, J. V. M. (2000): “Dertosa a l'antiguitat tardana. Consideracions sobre els espais cultuals”, Nous Col.loquis, IV, pp. 45-72.

ArbeloA, J. V. M. (2008): “Dertosa a l'antiguitat. Aspectes d'una estructura urbana incògnita", Citerior, IV, pp. 79-96.

Barrassetas, E. (1988): Informe-memòria de la recerca-campanya d'excavacions arqueològiques a la Plaça d'Alfons XII (Tortosa). Dept. Cultura Generalitat de Catalunya.

BAYerri, E. (1935): Historia de Tortosa y su comarca, vol. III. Tortosa.

BAYERri, E. (1960): Historia de Tortosa y su comarca, vol. viII. Tortosa.

Beltrán Lloris, M.; Mostalac, A. y Lasheras, J. A. (1984): Colonia Victrix Ivlia Lepida-Celsa (Velilla de Ebro, Zaragoza). La arquitectura de la "Casa de los Delfines". Zaragoza: Museo de Zaragoza.

(C) Universidad de Salamanca
Burch, J.; Nolla, J. M.; Palahí, L.; Sagrera, J.; Sureda, M. y Vivó, D. (2000): "La fundació de Gerunda. Dades noves sobre un procés complex de reorganització d'un territorio”, Empúries, LII, pp. 11-28.

CAmpo, M. (1984): "Tesorillo de denarios romano-republicanos hallado en Catalunya”, Saguntum, xviII, pp. 229-243.

Chasseigne, L.; Fincker, M.; Magallón, M. A.; Navarro, M.; Rico, C.; Sáenz, C. y Sillières, P. (2006): "Labitolosa and other Roman towns on the south side of the Pyrenees". En Abad, L.; Keay, S. y Ramallo, S. (eds.): Early Roman towns in Hispania Tarraconensis. Portsmouth, pp. 146-158.

Curto, A.; Loriente, A.; Martínez, R. y Ros, E. (1986): "Resultats de les excavacions arqueològiques portades a terme l'any 1984 a Tortosa (Baix Ebre)", Tribuna d'Arqueologia 1984-1985, pp. 115-120.

Del Amo, M. D. (1979): Estudio crítico de la necrópolis paleocristiana de Tarragona. Tarragona.

Diloli, J. y Ferrè, R. (2008): “Íberos en Tortosa. Nuevos datos sobre la protohistoria del Bajo Ebro", Saguntum, xL, pp. 109-125.

Diloli, J.; Ferrè, R.; Navarro, S. y Vilà, J. (2013): “Evolución urbana de un sector de la ciudad de Tortosa durante la Antigüedad: intervenciones arqueológicas en la calle de Sant Domènech", Archivo Español de Arqueología, Lxxxvi, pp. 75-90. http://dx.doi.org/10.3989/aespa.086.013.005

Diloli, J.; Ferrè, R. y VIlÀ, J. (2012): “Tortosa durante la protohistoria. Las excavaciones del Grup de Recerca Seminari de Protohistòria i Arqueologia de la URV entre 2004 y 2011 ”. En II Congreso Internacional Iberos del Ebro (Alcañiz-Tivissa, 2011). Tarragona, pp. 247-256.

Diloli, J.; Vilà, J.; González, A. y BeA, D. (2010): "Les excavacions arqueològiques al solar de l'antic I.E.S. del carrer Montcada (Tortosa, Baix Ebre)", Tribuna d'Arqueologia 2008-2009, pp. 59-86.

Genera, M. y Járrega, R. (2009): Aproximació a la Dertosa romana. Resultats de les excavacions arqueològiques al solar de la Costa de Capellans, n. ${ }^{\circ}$ 5. Tortosa (el Baix Ebre). Reus.

Griñó, D. y Camarasa, V. (2011): Memòria del control i excavació arqueològica de la urbanització del Portal dels Romeus, plaça de l'Absis, i carrer Capellans (Tortosa, Baix Ebre). Dept. Cultura Generalitat de Catalunya.

Guitart, J. (2006): "Iluro, Baetulo, Iesso, and the establishment of the Roman town model in Catalunya”. En ABAD, L.; Keay, S. y Ramallo, S. (eds.): Early Roman towns in Hispania Tarraconensis. Portsmouth, pp. 51-62.

GuitarT, J. (2010): "L'origen de les primeres ciutats romanes de Catalunya. Una aproximació des de l'arqueologia”, Catalan Historical Review, III, pp. 147-162.

JÁRREGA, R. (2006): "La problemàtica històrica i arqueològica de Dertosa: Estat actual dels coneixements i hipòtesis de treball”, Butlletí Arqueològic, xxviII, época v, pp. 137-197. 
JÁRregA, R. (2008): “La crisi del segle III a l'àrea compresa entre Tarraco i Saguntum. Aproximació a partir de les dades arqueològiques". En The countryside at the $3 \mathrm{rd}$ century. From Septimius Severus to the Tetrarchy. Gerona: Univ. de Gerona, pp. 105-139.

JÁrrega, R.; Ferrè, R.; Diloli, J. y VilÀ, J. (2014): “Elementos urbanísticos de abandono y una posible crisis estructural en la ciudad de Dertosa (Hispania Citerior) en el siglo il d. C.”. En Ramallo, S. F. y Quevedo, A. (eds.): Las ciudades de la Tarraconense oriental entre los siglos II-IV d. C. Evolución urbanistica y contextos materiales. Cartagena: Edic. Univ. de Murcia, pp. 149-174.

LÓPEZ VILAR, J. (2006): Les basiliques paleocristianes del suburbi occidental de Tarraco. El temple septentrional i el complex martirial de Sant Fructuós. Tarragona: ICAC.

Magallón, M. Á. y Navarro, M. (2010): "Las ciudades romanas en la zona central y occidental del Pirineo meridional veinte años después”, Pallas, LXxxiı, pp. 223-254.

Martín, M. (1995-96): "Observaciones sobre el urbanismo antiguo de Carthago Nova y su arquitectura a partir de sus condicionantes orográficos", Anales de Prehistoria y Arqueología, XI-XII, pp. 205-213.
Martín-Bueno, M. (1975): Bilbilis. Estudio histórico-arqueológico. Zaragoza: Univ. de Zaragoza-Diput. Prov. de Zaragoza-Ayto. de Zaragoza.

Martín-Bueno, M. (2000): “Bilbilis”. En Beltrán-Lloris, F.; Martín-Bueno, M. y Pina, F. (eds.): Roma en la cuenca media del Ebro. La romanización en Aragón. Zaragoza: Caja de Ahorros de la Inmaculada de Aragón.

Miravall, R. (1984): "Intervenció arqueològica al sòl del Patronat a Tortosa", Quaderns d'Història Tarraconense, v, pp. 207-222.

Miravall, R. (1988): Tortosa, any zero. Tortosa: ed. Dertosa.

Nolla, J. M. (2006): "The integration of NE Iberian communities and consolidation of the urban phenomenon". En Abad, L.; Keay, S. y Ramallo, S. (eds.): Early Roman towns in Hispania Tarraconensis. Portsmouth, pp. 44-50.

PayÀ, X.; Gil, I.; Loriente, A.; Molist, M. y Morán, M. (2003): "La ciutat romana d'Ilerda. Darreres aportacions al seu coneixement (Lleida, Segrià)". En Jornades d'Arqueologia i Paleontologia. Comarques de Lleida, pp. 279-312.

Pérez Almoguera, A. (1991): Lleida romana. Lérida: Pagès Editors. 
